\title{
Increased Drug Level
}

National Cancer Institute

\section{Source}

National Cancer Institute. Increased Drug Level. NCI Thesaurus. Code C54355.

A laboratory test result demonstrating an increased concentration of a specific drug. 